\title{
Correspondence
}

The Editor,

fournal of Glaciology

SIR,

\section{Subglacial water at the heads of Antarctic ice-stream tributaries}

The onset of enhanced flow of ice in East Antarctica, which has been shown recently to lead to the development of ice streams (Joughin and others, 1999; Bamber and others, 2000), is associated in a number of cases with the presence of subglacial "lakes". This observation shows that water is stored at the heads of enhanced-flow features, and provides an insight into (1) the potential role of subglacial water as a control on the flow of the interior ice sheet and, more generally, (2) the poorly known subglacial conditions of the Antarctic ice sheet.

Recent ice-flux calculations indicate that enhanced-flow features, which drain ice to the ice-sheet margin, penetrate deep in the interior of the Antarctic ice sheet. We have compared the locations of known Antarctic subglacial lakes (Siegert and others, 1996; Dowdeswell and Siegert, 1999, in press) with these ice-flux calculations (Fig. 1). Several lakes lie at the onset of major enhanced ice-flow features such as those feeding into Byrd and David Glaciers in East Antarctica, and Ice Stream B in West Antarctica (Fig. 1). A recent investigation into the dynamics of West Antarctic ice-stream

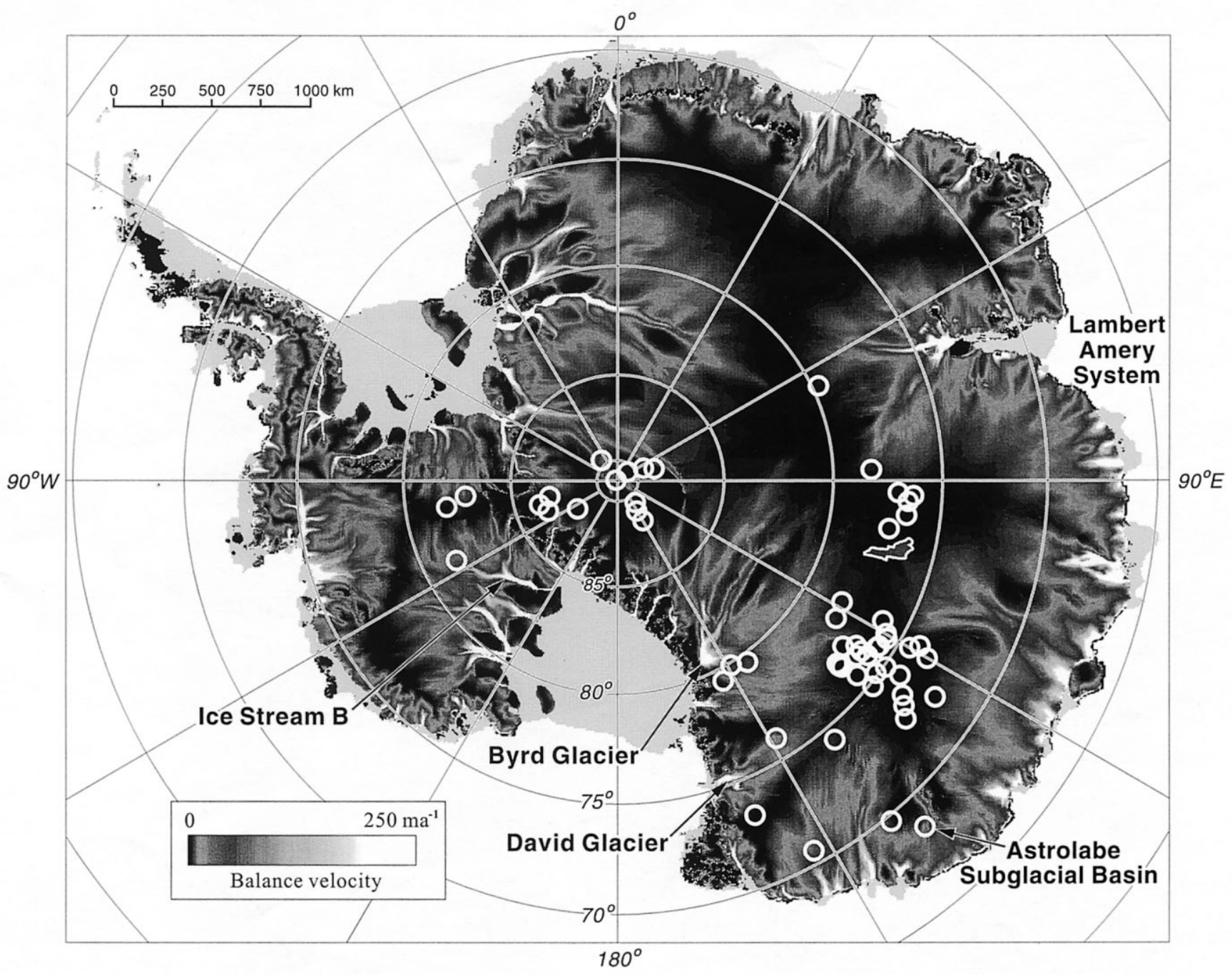

Fig. 1. Ice-sheet flux and the locations of known subglacial lakes (denoted as circles, the exact location being at the centre) across the whole Antarctic continent ( adapted from Bamber and others, 2000). A series of recently published datasets, derived from remote sensing and field measurements, is used as input to a numerical model (Budd and Warner, 1996), to calculate the ice-sheet balance flux. This flux is required to maintain the ice mass in steady state (i.e. where the mass gains equal the losses). Two datasets are required as model inputs: a digital elevation model (DEM) to calculate surface slope, and rates of accumulation of ice. The DEM used was a compilation derived from European Remote-sensing Satellite (ERS-1) radar altimetry and terrestrial data (Bamber and Bindschadler, 1997). Rates of accumulation were obtained from a new compilation of in situ and passive-microwave satellite measurements (Vaughan and others, 1999). This balance-flux model allows us to calculate the onset of enhanced ice flow marking the initiation of large Antarctic ice-drainage features. We do not point out which lakes we regard as most likely candidates for being near the onset of enhanced ice-sheet flow, because our data are not comprehensive and, if we did, we could not rule out the possibility that some other subglacial lakes may also be associated with enhanced ice flow. 
tributaries suggested that these features "could" be warmbased (Joughin and others, 1999). Our observation is evidence in support of this suggestion.

Subglacial lakes are likely to contain water and sediment at a ratio that is unknown. It is therefore possible that some subglacial lakes, especially those noted as "possible" lakes by Siegert and others (1996), are in fact pockets of watersaturated sediments. This, however, does not affect the implications of our observation, since it is indisputable that both subglacial lakes and water-saturated sediment pockets are evidence of liquid-water storage. We note that some ice streams have no subglacial lakes yet identified beneath their upstream tributaries. There are several explanations for the apparent absence of lakes in such areas. First, several enhanced ice-flow features have yet to be surveyed by airborne radar. Second, radar data from no more than a few flight-lines are available for any of the flow features, and it is highly possible that the existing lines missed relatively small lakes. Third, subglacial lakes are only able to build up where there are topographic hollows. In the absence of such topography, lakes are not able to form despite the presence of subglacial water. Fourth, subglacial-lake detection by radar methods is not possible if the ice base is "fluted" due to slidinginduced erosion, because radar energy is "scattered" by rough surfaces. Because of this, there may be only a narrow region of the ice sheet, between the enhanced-flow feature and the frozen ice-sheet base, where subglacial lakes can be detected. These explanations lead us to think that the presence of subglacial lakes in some onset regions of enhanced ice flow suggests there is likely to be subglacial water in other glaciologically similar regions.

Several subglacial lakes thought previously to be located in the slow-moving central region of the ice sheet are, in fact, at the margins of enhanced ice flow. Subglacial lakes near to South Pole are adjacent to an outlet glacier system deep within the Antarctic continent that flows into the FilchnerRonne Ice Shelf. This indicates that warm-based flow of ice (i.e. basal sliding and/or deformation of subglacial sediment) can initiate near the centre of the ice sheet, and extend continuously between this region and the margin of the ice sheet where ice streams terminate. Unless the ice-sheet base becomes frozen downstream of these lakes, which is improbable given the steady increase in ice flux calculated along these flow features, there should be a subglacial hydrological connection between the onset regions of enhanced flow, where our lakes are located, and the ice streams further downstream. Because of this, several enhanced-flow features that initiate in the inner Antarctic ice sheet can be thought of as being warm-based across their entire length. The identification of warm-based ice-sheet outlets is of value as a boundary condition to those building numerical models of the Antarctic ice sheet, since the subglacial thermal regime is critical to the flow of ice.

We note that lack of radar data in some regions means that our observation of subglacial lakes at the head of enhanced ice-flow features is not comprehensive. However, we hope that our finding will encourage other glaciologists to acknowledge the possibility of stored water at these locations, and accept that the ice sheet is warm-based along several relatively long ice-sheet outlets.

\section{ACKNOWLEDGEMENTS}

We thank R. Bindschadler for a constructive and helpful review, and M. Sturm for editorial guidance. Funding for this work was provided by U.K. Natural Environment Research Council grants GR9/4782 to M.J.S. and GR3/9791 toJ.L.B.

Bristol Glaciology Centre,

School of Geographical Sciences,

University of Bristol,

Bristol BS8 1SS, England

6 September 2000

\section{REFERENCES}

Bamber, J. L. and R. A. Bindschadler. 1997. An improved elevation dataset for climate and ice-sheet modelling: validation with satellite imagery, Ann. Glaciol., 25, 439-444.

Bamber, J. L., D. G. Vaughan and I. Joughin. 2000. Widespread complex flow in the interior of the Antarctic ice sheet. Science, 287 (5456), 1248-1250.

Budd, W. F. and R. .C. Warner. 1996. A computer scheme for rapid calculations of balance-flux distributions. Ann. Glaciol., 23, 21-27.

Dowdeswell, J. A. and M. J. Siegert. 1999. The dimensions and topographic setting of Antarctic subglacial lakes and implications for large-scale water storage beneath continental ice sheets. Geol. Soc. Am. Bull., 111, 254-263.

Dowdeswell, J. A. and M. J. Siegert. In press. The physiography of modern Antarctic subglacial lakes. In Fard, A. M., ed. Subglacial lakes: a planetary perspective. Boulder, CO, Geological Society of America. (GSA Special Paper.)

Joughin, I. and 7 others. 1999. Tributaries of West Antarctic ice streams revealed by RADARSAT interferometry. Science, 286(5438), 283-286.

Siegert, M. J., J. A. Dowdeswell, M. R. Gorman and N. F. McIntyre. 1996. An inventory of Antarctic sub-glacial lakes: Antarct. Sci., 8(3), 281-286.

Vaughan, D. G., J. L. Bamber, M. B. Giovinetto, J. Russell and A. P. R. Cooper. 1999. Reassessment of net surface mass balance in Antarctica: f. Climate, 12(4), 933-946.

SIR,

\section{The chemistry of grain boundaries in Greenland ice}

The spatial variation of impurities found in natural polycrystalline ice has been of interest for over a century. Based on thermodynamic arguments, Harrison and Raymond (1976) suggested that impurities in temperate glacier ice reside to varying degrees in three-grain intersections or triple junctions (TJs). Thus far, however, there have been only two studies of the microchemistry of natural ice. In the first study, Wolff and co-workers (Mulvaney and others, 1988; Wolff and others, 1988) showed, using X-ray microanalysis in a scanning electron microscope (SEM), that the TJs contained substantial concentrations of sulfate ions. The ice, obtained from Dolleman Island, Antarctica, was coated with aluminum and held at a temperature of $-160^{\circ} \mathrm{C}$ during analysis. Neither $\mathrm{S}$ nor $\mathrm{Cl}$ were detected elsewhere in the ice. Later, Fukazawa and others (1998) used micro-Raman spectroscopy to study ice from two Antarctic sites. At temperatures between $-8^{\circ}$ and $-35^{\circ} \mathrm{C}$ in Nansen ice, $\mathrm{NO}_{3}{ }^{-}$and $\mathrm{HSO}_{4}{ }^{-}$were found as liquids at the TJs, while at temperatures between $-8^{\circ}$ and $-20^{\circ} \mathrm{C}$ in South Yamato ice, $\mathrm{SO}_{4}{ }^{2-}$ was found as a liquid at the TJs.

The ice studied here was from an ice core (specimen depth $214 \mathrm{~m}$ ) at the Greenland Ice Sheet Project II (GISP2) site. It was stored at $-20^{\circ} \mathrm{C}$ at the National Ice Core Laboratory, Boulder, Colorado, U.S.A., before examination at Dartmouth. Specimens with dimensions of $\sim 25 \mathrm{~mm} \times 25 \mathrm{~mm}$ by $10 \mathrm{~mm}$ thick were cut from the ice, and the surface carefully shaved 